\title{
LA REBELIÓN DE LOS MORISCOS DE LA SERRANÍA DE RONDA (1570): GÉNESIS, OPERACIONES BÉLICAS Y DIMENSIONES DE UN CONFLICTO RESIDUAL DE LA GUERRA DE LAS ALPUJARRAS
}

\author{
Miguel Soto Garrido* \\ UNIVERSIDAD DE MÁlaGa
}

\begin{abstract}
RESUMEN
Tradicionalmente la historiografía sobre la rebelión de los moriscos ha prestado una atención prioritaria a la guerra de las Alpujarras, restando importancia a otros conflictos paralelos en el reino de Granada, merecedores de un auténtico análisis global. En el caso de la serranía rondeña, los moriscos se sublevarían en la primavera de 1570 tras las fatídicas operaciones de Antonio de Luna. Después de una fase de negociaciones, la guerra, enarbolada por los moriscos serranos más violentos frente a los rurales reducidos, sería dirigida por Luis Ponce de León, duque de Arcos, hasta comienzos de 1571. Durante estos meses la falta de medios de los cristianos nuevos generó una auténtica guerra de guerrillas en la que el dominio y conocimiento del territorio fue su principal aliado. Tras la expulsión de los moriscos, la continuidad de cuantiosos colectivos refugiados en la sierra condicionó su pervivencia en un acusado bandolerismo que coincide cronológicamente con la nueva etapa repobladora.
\end{abstract}

PALABRAS CLAVE: reino de Granada, Serranía de Ronda, guerra de Granada, moriscos, esclavitud

*miguelsoto1997@gmail.com 


\title{
THE MOORISH REBELLION OF THE MOUNTAIN RANGE OF RONDA (1570): ORIGIN, MILITARY OPERATIONS AND DIMENSIONS OF A RESIDUAL CONFLICT IN THE ALPUJARRA'S WAR
}

\author{
Miguel Soto Garrido* \\ Universidad de Málaga
}

\begin{abstract}
Traditionally, historiography studies about the moorish rebellion have been paying a priority attention to the Alpujarra's War, taking out importance to other similar conflicts in the kingdom of Granada, whose deserve a real global research. In the case of the Mountain Range of Ronda, moorish rose in rebellion in the spring of 1570 after Antonio de Luna's fateful operations. After a phase of dealt several, the war, entreed by the most violent mountain moorish, in front of the reduced rural ones, it would be led by Luis Ponce de Leon, duke of Arcos, until the beginning of 1571. During this stage, the lack of means of the new christians generated an authentic guerrilla war in which the dominion and knowledge of the territory was their main ally. After the expulsion of the moorish, the continuation of large groups of refugees in the Sierra conditioned their survival in a banditry defendant who coincides chronologically with the new repopulated stage.
\end{abstract}

KEY WORDS: kingdom of Granada, Mountain Range of Ronda, war of Granada, moorish, slavery

\footnotetext{
*miguelsoto1997@gmail.com
} 


\section{UNA APROXIMACIÓN HISTÓRICA ${ }^{1}$}

Desde la segunda mitad del siglo XX los estudios sobre la cuestión morisca en general, y sobre el reino de Granada en particular, despertaron un creciente interés historiográfico, con una importante nómina de autores que progresivamente fueron aportando señeras investigaciones sobre el tema. Como no podía ser de otra forma, la rebelión de los moriscos recibió una atención especial como prolegómeno de la etapa repobladora que tanta disposición despertó a finales de siglo. Autores como M. Barrios Aguilera, B. Vincent, R. Benítez Sánchez-Blanco, V. Sánchez Ramos o J. Castillo Fernández, entre otros, sin duda legaron estudios referenciales acerca de la guerra morisca granadina. Ahora, la inmensa mayoría de estas investigaciones tomaron como objeto de estudio la guerra de las Alpujarras, nomenclatura académica que reduce geográficamente la contienda a tal entorno montañoso. Sin embargo, no podemos olvidar la existencia de otros focos bélicos paralelos en otras regiones del reino, de trascendencia histórica semejante, pero que, en clave historiográfica, han sido relegados en consideración frente al conflicto alpujarreño.

La rebelión de los moriscos de la Serranía de Ronda (1570) estalla tardíamente en el conjunto de la guerra de las Alpujarras, siendo considerada desde ese mismo instante como un conflicto residual dentro de un entramado más amplio cuyos verdaderos designios se libraban en la región central del reino. Ahora bien, este "carácter residual" no resta importancia al episodio histórico, fundamentalmente por la riqueza de las fuentes históricas existentes para su análisis. De ahí la necesidad no solo de poner en relieve la importancia de la contienda rondeña y toda su complejidad interna, que no es poca, sino también calibrarla correctamente en la guerra en la que se inserta, con el propósito de avanzar en el conocimiento de la rebelión morisca en el reino de Granada.

La guerra de las Alpujarras, prendida en el Albaicín en la Navidad de 1568 , se extendería hasta bien entrado el año 1570 y estuvo dividida en varias fases. Tras la proclamación de Aben Humeya y los intentos de constitución

1. El presente trabajo es resultado de una beca de Iniciación a la Investigación proporcionada por el Plan Propio de Investigación de la Universidad de Málaga y desarrollada en el Departamento de Historia Moderna y Contemporánea de dicha universidad. Agradecemos a la Universidad de Málaga la financiación concedida y, en especial, al profesor Juan Jesús Bravo Caro su constante apoyo y orientaciones en el desarrollo de esta investigación. 
de un "Estado" en la Alpujarra, las tropas dirigidas por los marqueses de Mondéjar y Vélez se ponían al frente. Por el contrario, el disentimiento entre los propios cristianos favoreció la expansión del conflicto. Tampoco la irrupción de don Juan de Austria como nuevo eje rector de la contienda parecía contener la propagación hacia el oeste y las tierras de Málaga.

Tras un sangriento primer año de hostilidades, el contexto mediterráneo minó la moral de las autoridades. Los contactos y auxilios del norte de África eran conocidos, pero a comienzos del 1570 se produjo la caída de Túnez. Entonces la guerra daría un vuelco intenso. Los ejércitos de don Juan de Austria, el duque de Sessa y Antonio de Luna arremetieron con una ofensiva que consiguió vislumbrar los primeros destellos de una victoria. Las divisiones en el lado morisco afloraron de forma intensa y mientras los enfrentamientos, de mayor o menos importancia, se iban sucediendo, parecía que la guerra había tomado un partido claro.

Empero, la primavera y el verano trajeron un nuevo panorama. Los nuevos contactos con Argel fueron paralelos a la apertura de nuevos focos: Vélez-Málaga, Sierra Bermeja y la Serranía de Ronda. En este contexto la expulsión de los moriscos se iba planteando como la solución efectiva para acabar con el conflicto y, como expondremos, en esta fase final las tierras rondeñas se sumaron al conflicto.

\section{LA SERRANÍA DE RONDA}

\subsection{Los condicionantes geográficos}

El doctor Gil Sanjuán sintetizó magistralmente el contenido históricogeográfico de la Serranía de Ronda al reseñarla como: "una serie de alineaciones montañosas que forman profundos y aislados valles, de difícil acceso, dando lugar a un mundo aparte, y definiendo la peculiaridad de esa comarca" 2 . En efecto, aún siendo un área muy poco agraciada por la naturaleza, se alza como uno de los conjuntos geográficos de Andalucía con más personalidad de su entorno ${ }^{3}$. Su posición geoestratégica es muy singular: ubicada entre las serranías de Grazalema y Ubrique, la depresión de Antequera, la Hoya de Málaga, el sector más occidental de la Costa del Sol y el Campo de Gibraltar ${ }^{4}$.

2. J. Gil Sanjuán (1991), 229.

3. F. Rodríguez Martínez (1977), 3.

4. Ibidem. 
Este imponente conjunto geográfico, lejos de presentar una cierta unidad, lo vemos segmentado en múltiples regiones, revestidas cada una de características propias. Podemos distinguir dos grandes zonas: la altiplanicie de Ronda, con la urbe en su centro como núcleo jerarquizador del territorio, y por otra parte, los sectores montañosos del norte (Cuevas del Becerro-Serrato), este (El Burgo-Yunquera) y los valles del suroeste (Genal y Guadiaro)

Geográficamente, el valle del Genal y del Guadiaro constituyen dos comarcas intramontañosas en torno a sendos ríos que les dan nombre. Independientes entre sí, pero necesariamente interconectados, ambos valles acogen entre sus escarpadas estribaciones montañosas numerosos asentamientos en aquellas terrazas más o menos habitables. Estas, junto a los numerosos núcleos de carácter más rural -antiguas alquerías-, constituyen por excelencia los pueblos moriscos popularmente encuadrados en la denominación de Havaral, término de origen bereber referente a las poblaciones del Alto $\mathrm{Genal}^{6}$, en diferenciación de los habitantes de la propia ciudad de Ronda.

Sería en esta región, de carácter eminentemente montañoso y en cierto modo pobre, excluyendo las zonas más fértiles cercanas a los ríos, donde la comunidad morisca desarrollase sus ciclos vitales. Este peculiar carácter geográfico nos está hablando de un auténtico paisaje morisco, resultado de "unas prácticas culturales, religiosas y sociales que propiciaron una identidad muy vinculada a determinadas visualizaciones del paisaje, con un marcado acento condicionante de la misma estructura económica"7.

De hecho, F. Martínez Rodríguez afirma estar ante lo que se puede denominar una auténtica "Alpujarra malagueña". Esta nomenclatura tiene una profunda razón de ser si tenemos en cuenta los sucesos que tendrán lugar en la segunda mitad del siglo XVI en el contexto de la guerra de las Alpujarras. La rebelión iniciada tardíamente en la Serranía de Ronda carece de fundamento si no la encuadramos en su debido contexto geográfico. No en vano, la propia geografía, desde un primer momento, condicionó todo conflicto y se convirtió en el principal aliado morisco para combatir los contingentes cristianos. El profundo conocimiento del terreno, el dominio de las zonas montañosas más escarpadas, la distracción de las tropas en las laberínticas montañas, el recurso a la huida a los lugares más recónditos -fuera de cualquier jurisdicción efectiva- o, por otro lado, los contactos con el norte de África por los senderos que, ocultamente desde las cimas,

5. Ibidem.

6. V. Martínez Enamorado y J. A. Chavarría Vargas (2010), 98.

7. J. J. Bravo Caro y P. Ybañez Worboys (2018), 74. 
llegaban a la costa, son fenómenos presentes en este marco geográfico donde desarrollarán su actividad los llamados monfíes y surgirá posteriormente la rebelión armada. Sin estos puntos difícilmente puede comprenderse el devenir de los acontecimientos en la zona.

\subsection{Antecedentes históricos (siglos XV-XVI)}

Geográfica y políticamente, la Serranía de Ronda constituía la región más occidental del reino de Granada, desempeñando desde la Baja Edad Media un papel de tierra de frontera entre dos mundos ${ }^{8}$. Tras la conquista de la ciudad de Ronda y posteriormente su serranía por los Reyes Católicos se impuso la decisión regia de mantener a los mudéjares únicamente en las zonas rurales y reemplazarlos en las ciudades por contingentes de repobladores cristianos, algo que, por lo demás, era habitual ${ }^{9}$. Así, el mundo rural permanecía incólume, pues bajo las pautas del mudejarismo los antiguos moradores rurales proseguirían realizando sus quehaceres agrícolas como era costumbre. Quedaba configurada, por tanto, una distribución un tanto desigual: un $70 \%$ mudéjares frente a un $30 \%$ de repobladores cristianos.

Lo cierto es que, desde un primer momento, los mudéjares fueron tratados como vencidos. A la prohibición de los contactos entre la serranía y la ciudad, y la posesión de armas se sumaba su consideración regia como fuente de ingresos y el hecho de que la élite rectora cristiana estaba impregnada de la ciega ideología cimentadora de la conquista ${ }^{10}$. Ni siquiera el recurso a la cuestión señorial dio los resultados esperados, sino que atizaron la crisis mudéjar ${ }^{11}$.

Todo ello surgió en un momento en que los monarcas empezaron a materializar la conversión general del reino de Granada. No debemos olvidar que a pesar de las directrices contenidas en los tratados de capitulación, los Reyes Católicos consideraron la religión musulmana de sus vasallos como un trance provisional, vislumbrando los medios que desembocarían en una no muy lejana reconciliación ${ }^{12}$.

Según J. E. López de Coca Castañer, las conversiones en el área rondeña se produjeron en sintonía cronológica con las del resto del obispado

8. M. Acién Almansa (1979), 131-132.

9. Ibidem, 315 .

10. Ibidem, 331.

11. E. Pérez Boyero (1997), 29.

12. J. E. López de Coca Castañer (1996), 520. 
de Málaga, en el otoño de 1500; eso sí, encontrando en la región una notable resistencia ${ }^{13}$. Únicamente la intervención armada en la primavera de 1501, con la presencia del propio rey Fernando, logró, en mayo, reducir el conflicto, cuando derrotados, se convirtieron al cristianismo ${ }^{14}$. Ahora en la praxis, bajo la práctica islámica de la taqiyya, el mantenimiento de sus usos y costumbres culturales fue una realidad inobjetable hasta el estallido de la rebelión morisca en el reinado de Felipe II $^{15}$.

En cualquier caso no todos se quedaron tras la revuelta. Ante una comunidad desarticulada para emprender una sublevación efectiva y sobre la que se aplicaron rigurosas medidas de posesión de armas como garantía de paz, los contactos y apoyos de los norteafricanos constituyeron el siguiente estadio ${ }^{16}$. En este caso sí se aprecia un descenso demográfico notable en los años inmediatamente posteriores, correspondientes a los moriscos emigrados a allende ${ }^{17}$. Muchos poblados conocieron una pronunciada despoblación, que fue solventada con una repoblación cristiana, sobre todo, en aquellos más importantes y cercanos a enclaves fortificados ${ }^{18}$.

El estado global de la serranía tras las conversiones forzadas era desastroso, intensificando la crisis demográfica vivida en la transición entre el fenómeno mudéjar y el morisco ${ }^{19}$. Según la recaudación del servicio de 1504, las pérdidas poblacionales de la vicaría de Ronda fueron del $50 \%$, suponiendo el porcentaje de pérdidas más alto de todo el reino ${ }^{20}$.

Así pues, los moriscos de la Serranía de Ronda, más allá de noticias puntales, con la presente evolución y tesitura presentada, permanecerían como un colectivo ciertamente pacífico, sin presentar grandes alteraciones hasta la sublevación de las Alpujarras. De hecho, tras la revuelta mudéjar y las conversiones, en 1505, se reformó el sistema parroquial en el obispado malagueño, tejiendo una red de parroquias rurales destinadas a la instrucción cristiana de sus pobladores ${ }^{21}$. Totalmente fracasada en sus propósitos, la continuidad cultural y religiosa fue rotunda.

13. J. E. López de Coca Castañer (1993-1994), 203.

14. B. Vincent y A. Domínguez Ortiz (1978), 19.

15. L. Cardaillac (1979), 88-90.

16. A. Galán Sánchez y R. G. Peinado Santaella (1997), 77.

17. Ibidem, 78.

18. F. Siles Guerrero (2011), 220.

19. A. Galán Sánchez (1982), 275.

20. A. Galán Sánchez y R. G. Peinado Santaella (1997), 74.

21. J. Suberbiola Martínez (1985), 318. 
Además, parece que la actuación inquisitorial en la serranía y el control de las minorías confesionales fue, en cierto modo, laxo tanto por la lejanía del tribunal como por lo áspero y tortuoso del territorio ${ }^{22}$. En cualquier caso, los datos con que contamos son harto sugerentes para calibrar la situación. La visita inquisitorial de 1560, que repasó las vicarías de Marbella, Coín y Ronda, nos da buena muestra del mantenimiento de las costumbres moriscas en los núcleos de la serranía (rituales funerarios, zambras y leilas, baños y lavatorios, degüelle de los animales, etc. $)^{23}$. De hecho, todos los pueblos visitados recibieron condenas por islamismo, destacando los casos de Alpandeire, Cartajima o Istán ${ }^{24}$. Años más tarde, en la visita de 1568, aún siendo las cifras menos representativas, se constatan de nuevo estas persistencias ${ }^{25}$.

Esta realidad cultural cuadra con los noticas acerca de la geografía morisca para estos momentos. Según las estimaciones realizadas por Arévalo de Zuazo para 1568, el sector occidental del obispado de Málaga, incluyendo 32 lugares pertenecientes a la jurisdicción de Málaga, Marbella y Ronda, junto a sus señoríos, presentaba una población mayoritariamente morisca. Las cifras eran del $87,3 \%$ de moriscos frente a un $12,7 \%$ de población cristiano vieja ${ }^{26}$, lo que nos sigue dando las claves de que en estos instantes del siglo XVI aún no podemos hablar de una minoría. Todo queda en un contexto de endurecimiento de Felipe II con respecto a la erradicación de esta cultura islámica, que recuperó la intransigencia del espíritu del sínodo provincial de Granada.

En este sentido, y como antecedente a la rebelión posterior, es imprescindible mencionar el fenómeno monfí como precedente histórico de relevancia para lo que posteriormente acaecería en la Serranía de Ronda. El término monfí - procedente del árabe y que significa desterrado o exiliado ${ }^{27}$ - hace referencia a aquellos moriscos rebeldes que enarbolan la causa contra las autoridades cristianas una vez quebradas las capitulaciones. Para ello se refugian en la sierra, desde donde atacan, roban y persisten ${ }^{28}$. Este fenómeno, fruto de la coexistencia de ambas comunidades y de los intentos de asimilación sobre los moriscos, presente desde la década los años veinte, fue cobrando fuerza

22. J. Gil SAnjuÁn (1991), 233.

23. M. I. Pérez De Colosía Rodríguez (1986), 338.

24. Ibidem, 342.

25. J. Gil Sanjuán (1978), 325.

26. J. J. Bravo Caro (1991), 220.

27. B. VinCENT (1987), 176.

28. A. Torremocha Silva (2006), 279. 
a lo largo del siglo XVI para adquirir una especial virulencia en época de Felipe II ${ }^{29}$. La Serranía de Ronda apenas se vio afectada por los salteadores monfies hasta el comienzo de la guerra. Habría que esperar al avance del conflicto para conocer la efervescencia del bandolerismo.

Cuando la rebelión de las Alpujarras estalló en la Navidad de 1568, exceptuando el alzamiento de Istán, rápidamente reprimido, la serranía permaneció ajena al conflicto que desangraba las regiones centrales y orientales del reino de Granada. Solo los movimientos militares en Sierra Bermeja tuvieron un eco en la vecina serranía rondeña y, con ello, las autoridades cristianas tomaron medidas para combatir a los monfíes de la zona $^{30}$. Aún así, sería tardíamente, en la primavera de 1570, -con la Alpujarra considerablemente más apaciguada- cuando la Serranía de Ronda, por unas motivaciones muy concretas se sumó a la guerra que desde años atrás venían haciendo sus correligionarios ${ }^{31}$

\section{3. "LA JORNADA Y SUÇESSO DE LA GUERRA DE RONDA" (1570)}

\subsection{El estallido de la sublevación en la serranía (abril-mayo de 1570)}

El acontecer de los hechos desde el estallido de la rebelión en la Navidad de 1568 motivó en la primavera de 1570 la decisión regia de sacar a los moriscos de paces del reino granadino. Es decir, aquellos correligionarios que no se habían sublevado, pero que, como miembros de la comunidad morisca, a ojos de las autoridades, no dejaban de despertar desconfianza en la medida que podían auxiliar a los insurgentes ${ }^{32}$. No deja de ser cierto que muchos de ellos, aunque no participaron en el levantamiento, sí fueron cómplices de los hechos perpetrados y, por ende, susceptibles de ser juzgados con la severidad legal correspondiente ${ }^{33}$. En cualquier caso, la raíz de la cuestión era que ninguna categoría de morisco era "garantía de un sometimiento efectivo" 34 y la expulsión global era considerada como una medida necesaria de cara a la consecución de la paz en el reino de Granada ${ }^{35}$.

29. B. Vincent y A. Domínguez Ortiz (1978), 29.

30. Archivo de la Real Maestranza de Caballería de Ronda, Archivo Privado de Rafael Aguilera, legajo 004-026 (4944), "Sobre dar salario a quien fuere a buscar Monfíes".

31. R. Benítez Sánchez-Blanco (1982), 176; L. del Mármol Carvajal (2015), 670-671.

32. R. Benítez Sánchez-Blanco (2010), 27.

33. Ibidem, 27.

34. M. Barrios Aguilera (2008), 352.

35. V. SÁnchez Ramos (1995), 374. 
Tras la génesis de esta operación subyacía la intransigencia del cardenal de Sigüenza, Diego de Espinosa, antiguo inquisidor general, a la sazón, presidente del Consejo Real y principal consejero de Felipe II $^{36}$. Sería este cortesano quien ordenase a finales de febrero-comienzos de marzo de 1570 sacar a todos los moriscos de paces de la jurisdicción granadina, decisión tomada por una persona, como indica Cabrera de Córdoba, poco docta en cuestiones militares ${ }^{37}$. Este criterio de actuación suponía tratar con el mismo rasero a una comunidad nada homogénea en actitudes ante el levantamiento. De tal forma, la incomprensión regia del carácter pacífico de este colectivo y la entrega de muchas de sus propiedades a repobladores, a la par que muchas de sus familias eran esclavizadas, generó unos resultados totalmente opuestos a los esperados ${ }^{38}$.

Por una parte, cuantiosos colectivos de moriscos empezaron a cobijarse en la intrincada orografía de la sierra para alimentar la efervescencia del bandolerismo, lo que dio lugar a batidas militares para reducirlos, siendo muy destacables las de Sierra Nevada y Sierra de Cogollos ${ }^{39}$. Por otro lado, desde el recurso a la montaña u otros medios, muchos moriscos de paces decidieron alistarse a la guerra contra el monarca ${ }^{40}$. Estas adhesiones, lejos de limitarse a la zona alpujarreña, conocieron una extensión territorial hasta puntos relativamente lejanos al conflicto, como el caso que nos ocupa, la Serranía de Ronda.

Si la condición de moriscos de paces hacía referencia a su carácter pacífico en relación a los insurrectos, esta postura ante el conflicto se ejemplificaba a la perfección en los núcleos dispersos por las enmarañadas tierras de Ronda. La comunidad morisca serrana, a lo largo del siglo XVI, había constituido un fiel colectivo a la Corona, que cumplía con sus obligaciones impositivas y protagonizaba sus quehaceres tradicionales sin alteraciones destacables. De hecho, una de las escasas referencias documentales previas al levantamiento trata del préstamo pedido al pósito de Casares para posibilitar la ejecución de las labores de siembra ${ }^{41}$.

Sin embargo, el deseo regio de expulsar a los moriscos de paces y su intento de materialización en la Serranía de Ronda vendría a tornar

36. R. Benítez Sánchez-Blanco (1982), 181.

37. Ibidem, 182.

38. V. Sánchez Ramos (1995), 374.

39. V. SÁnchez Ramos (2000), 532.

40. Ibidem, 532.

41. R. Benitez Sánchez-Blanco (1982), 176. 
forzosamente la situación hacia un belicoso e incierto devenir. Antonio de Luna fue el encargado de "despoblar los lugares de la Sierra de Ronda" 42 . Para ello, partió desde Antequera en abril de 1570 surtido de infantes y caballería de la guardia de la ciudad con destino a Ronda, donde aumentaría sus efectivos de la mano del corregimiento rondeño ${ }^{43}$. La operación preveía la distribución de los contingentes por distintos puntos geoestratégicos del Havaral. Desde ellos habrían de empezar las operaciones destinadas a la reunión de los moriscos en puntos determinados, preferiblemente iglesias, para su posterior repartimiento por diversas localidades de la península ibérica ${ }^{44}$. Se contemplaba el dominio previo de los puntos montañosos antes de la intervención en los núcleos rurales y urbanos, dado que eran lugares de posible refugio una vez que los moriscos constatasen lo que iba a acaecer. A ello se sumaba el establecimiento de una sólida guarnición en Jubrique, centro neurálgico, como punto de apoyo y posible refuerzo a las operaciones paralelas en otros sectores de la serranía ${ }^{45}$.

El idílico planteamiento de la operación pronto dio al traste en la praxis militar. El rotundo fracaso estuvo determinado principalmente por la propia geografía de la zona, extraordinariamente conocida por sus moradores moriscos, pero difícil de sortear para unas tropas nada especializadas en el oficio de la guerra. Ciertamente, en la composición de los contingentes interventores era palpable la exclusividad del componente concejil circundante. En palabras de Mármol "gente bisoñada y mal disciplinada" 46.

El bando de expulsión de los moriscos de paces de la Serranía de Ronda sería promulgado a comienzos del mes de mayo. Tal y como reza el documento:

... por orden de su magestad se levantaron y llevaron los moriscos de pazes desta comarca y manda que ninguno este en esta ciudad ni en otra ninguna villa ni lugar deste reyno de Granada aunque sean vesinos desta ciudad ni

42. L. del Mármol Carvajal (2015), 670.

43. Mientras que Hurtado de Mendoza ubica la expedición en el mes de mayo, Mármol Carvajal presenta el mes de abril, esta última fecha realmente verídica al contrastarse con la documentación epistolar. De hecho, Felipe II escribe a Ronda el 4 de mayo al enterarse del descalabro ocurrido en la sierra. R. Benítez Sánchez-Blanco (1982), 176.

44. Al igual que en el caso anterior, Mármol y Hurtado no coinciden en el hipotético destino de los moriscos, decantándose aquel por la baja Andalucía y la "raya de Portugal" y este por las tierras castellanas.

45. D. Hurtado de Mendoza (1970), 365-366; L. del Mármol Carvajal (2015), 673.

46. L. del Mármol Carvajal (2015), 674. 
que ninguna persona los encubra por lo qual y por lo que los moriscos desta comarca estan todos alçados y levantandos... ${ }^{47}$.

En este sentido, de cara al análisis de esta intervención, es necesario calibrar varios factores en su justa medida. La presencia de la comunidad morisca, en algunas zonas en proporciones sustancialmente mayores a la de cristianos viejos y sus interacciones con estos, determinó la articulación de un cuerpo militar disciplinado, equipado y permanente. Bajo la jurisdicción de la Capitanía General del reino, quedó asignado al linaje de los Mendoza $^{48}$. La importancia de este cuerpo, más allá de su profesionalidad y estructuración, radicaba en que su financiación era costeada directamente por los moriscos a través de los servicios o fardas mayores y las fardas costeras $^{49}$. Previsiblemente, en esta tesitura, el papel desempeñado por las milicias concejiles, si no podemos tildarlas de estar en plena decadencia como en el interior de Castilla, deberíamos hablar -con claras excepciones como el caso malagueño ${ }^{50}$ - de "un papel auxiliar y de apoyo" a los cuerpos de la Capitanía ${ }^{51}$. De ahí procede el carácter irregular de sus aportaciones, la reticencia concejil a su concesión para apoyo militar así como su nula formación, equipamiento y tendencia al botín ante todo ${ }^{52}$. Este último aspecto es fundamental a la hora de explicar en buena medida la "crueldad innecesaria" tan conocida en este conflicto ${ }^{53}$.

En efecto, ante la acción de estos contingentes con el premeditado fin, aquellos individuos más capacitados huyeron a la sierra, totalmente desconocida e inmanejable para los efectivos militares. Desde allí, al abrigo y protección de la montaña, enarbolaron la resistencia y emprendieron ataques contra las autoridades. A la par, las ineficaces huestes concejiles, ávidas de riqueza, acometían el robo y la esclavización de las mujeres y niños, colectivos sociales más indefensos: "habia tantos interesados que por eso solo fueron tomados por enemigos" ${ }^{54}$. Todo ello nos da las premisas de un fracaso militar en toda regla. Como señala el propio Hurtado de Mendoza,

47. Archivo Histórico de la Nobleza (AHNOB), Archivo de los Condes de Luque, C. 750, D. 2 , fols. $2 \mathrm{r}-2 \mathrm{v}$.

48. A. JimÉnez Estrella (2009), 80.

49. A. JimÉnez Estrella (2004), 41.

50. P. Pereiro Barbero (1985), 368; J. M. Ruiz Povedano (2017), 204-206.

51. A. Jiménez Estrella (2009), 80.

52. M. Barrios Aguilera (2008), 355.

53. A. Galán Sánchez (1991), 26-28; J. Castillo Fernández (2015), 33.

54. D. Hurtado de Mendoza (1970), 367. 
a los moriscos de paces serranos "les habían quebrantado la seguridad y palabra del Rey, que tenían como por religión o vínculo inviolable" 55 . No dejamos de ver esa "cierta identificación con los vencidos" en oposición al "orgullo de los vencedores" que también mostró Mármol pues, a la postre, no estaban sino relatando el genocidio de un pueblo enraizado desde hace siglos en sus tierras ${ }^{56}$. Todo lo contrario, llama la atención el hecho de que Pérez de Hita omita esta primera operación y no se adentre en el análisis de la motivación general de la rebelión, obviando las tropelías de los soldados cristianos y otros datos esenciales en el conflicto ${ }^{57}$.

La operación, que contribuyó a forzar el levantamiento de los moriscos del agreste alfoz rondeño, supone el punto de partida para el análisis de los acontecimientos bélicos sucedidos a partir de ese momento. La evolución pacífica de la región a lo largo de la centuria quedaba quebrada por un conflicto bélico prolongado hasta comienzos de 1571. En un primer momento el rey comisiona al corregidor rondeño Pedro Bermúdez la pacificación de la zona, pero, infructuosamente, abandona el encargo, siendo sustituido por el duque de Arcos en el mes de mayo de ese año.

En este horizonte las operaciones que asolaban el antiguo solar nazarí llevaron parejas el auge del esclavismo, de forma que la rebelión alpujarreña marcó determinantemente la institución de la esclavitud hasta, al menos, la década de los noventa ${ }^{58}$. Este episodio implicaba una cuestión harto delicada, pues la esclavitud era practicada ante súbditos del rey, pertenecientes a una comunidad teóricamente cristiana, lo que daría no pocos problemas jurídicos y de legitimación en un futuro inmediato ${ }^{59}$. En el ámbito malacitano, Arévalo de Zuazo, desde el corregimiento de Málaga, dispuso un auto para que los niños y niñas capturados y tomados por esclavos durante la rebelión fuesen mantenidos y criados por sus amos en la religión católica, hasta alcanzar la edad estipulada en que quedarían libres ${ }^{60}$.

En la zona rondeña, la actuación de Antonio de Luna supuso el precedente más inmediato para la inauguración plena del esclavismo en la serranía. Practicado por la población de cristianos viejos, grupos de bandoleros y soldados, se mantendría a lo largo de los diez meses que duró el

\section{Ibidem.}

56. J. Castillo Fernández (2015), 29.

57. J. Gil Sanjuán (1997), 132-133; G. Pérez de Hita (1997), 314.

58. J. J. Bravo Caro (1998b), 144.

59. A. Martín Casares (1998), 346.

60. Archivo Municipal de Málaga, Colección de Originales, vol. 37, fol. 429r. 
enfrentamiento, alimentando el mercado esclavista con dirección a Málaga y la baja Andalucía. En la zona malagueña ya había sido practicado con anterioridad, desde 1569, con una especial incidencia al colectivo infantil, como han estudiado varios autores ${ }^{61}$.

\subsection{La entrada del duque de Arcos y las negociaciones (mayo-julio de 1570)}

De cara a un análisis riguroso, como ya señaló el profesor R. Benítez Sánchez-Blanco, no podemos desvincular los acontecimientos acaecidos en la zona estudiada con los producidos en la región central y oriental del reino, pues la metodología, el trasunto del conflicto o las medidas puestas en marcha participan de aquella. Sin embargo, tampoco es posible obviar su "relativa independencia" con respecto a la Alpujarra o la presencia de una serie de notas peculiares que confieren al conflicto rondeño una "identidad propia" ${ }^{2}$.

El área rondeña, pese a ser bastante más reducida territorialmente que la Alpujarra, no estaba exenta de dificultades y/o ventajas -en función de las partes- y se hacía necesario la presencia de una cabeza rectora que liderara el conflicto. Tales requisitos encontraron un perfecto acomodo en la figura de Luis Cristóbal Ponce de León, II duque de Arcos, y una de las grandes personalidades del momento. La entrega de esta tarea militar no suponía una casualidad, pues el duque, junto a sus incuestionables dotes militares, era titular del condado de Casares, señorío que aunaba considerable población morisca sublevada, siendo uno de los principales interesados en el fin de los problemas.

Por otro lado, no podemos dejar de tener en cuenta un aspecto a insertar en este análisis. A pesar de que la Monarquía hispánica durante el siglo XVI había protagonizado una disminución de la participación de la nobleza en los menesteres militares, la estructuración de los quehaceres bélicos aún seguía pivotando en torno a la aristocracia y a unos valores nobiliarios sustentados en unos parámetros ideológicos puramente medievales ${ }^{63}$. En un momento tan avanzado como el reinado del Rey Prudente, buena parte de las motivaciones para realizar la guerra iban en esta línea caballeresca (las redes clientelares, el recuerdo de un pasado glorioso, el deseo de en-

61. J. M. Rabasco Valdés (1975), 293-302; R. Benítez Sánchez-Blanco (1974), 31-54.

62. R. Benítez Sánchez-Blanco (1982), 175.

63. D. García Hernán (2000), 289. 
grandecimiento del linaje, etc.), lo que tenía su evidente correlato en las retribuciones regias en forma de cargos y prebendas como recompensa a los servicios prestados ${ }^{64}$. Además, este activo papel de la nobleza en la guerra incrementaría su autoridad social y política, sobre todo, tras la caída del sistema de reclutamiento administrativo único ${ }^{65}$.

Si trasmutamos estos esquemas a nuestro caso de estudio, junto a lo referido, en el hecho de que el duque de Arcos asuma la dirección de la guerra se debe insertar otra variable: las intenciones del propio noble en su ascenso en la corte ${ }^{66}$. En efecto, la orientación del conflicto queda planteada para un temprano pacto con los moriscos, para, sin tener que invertir grandes sumas de dinero, escalar en el cursus honorum cortesano. Estas medidas pacifistas e interesadas, muy alejadas de las habituales formas violentas emprendidas, a la postre, resultaron ineficaces y le ocasionaron al duque serías críticas en la corte, en especial por parte de don Juan de Austria ${ }^{67}$. Sin embargo, las divergencias entre el hermanastro del soberano, encargado de la contienda alpujarreña, y el propio duque fueron una constante mantenida a lo largo de todo el conflicto, sobre todo, en sus momentos iniciales. El duque aspiraba a coordinar las operaciones militares bajo la dirección única de Felipe II, en un intento de esquivar la posición preeminente de don Juan de Austria.

En cualquier caso, Ponce de León era el encargado de poner remedio a una situación que, por la evolución global del conflicto, no debía demorarse en exceso. Por ello, fracasadas las operaciones de los protagonistas anteriores, el cardenal de Sigüenza escribió al duque a finales de mayo de 1570 anunciando la aceptación de lo que consiguiese pactar con los moriscos ${ }^{68}$. Así, allá por el mes de mayo tomó como centro de operaciones la villa de Casares para, antes de arremeter las armas, discurrir por la senda pactista que, a priori, tenía planeada ${ }^{69}$.

Amén de dichas intenciones, y al respecto de las crónicas, el noble organizó el envío de una comitiva a terreno hostil dando a conocer a la comunidad morisca sus anhelos pactistas. El acto habría fructificado con la concertación de un encuentro en una ermita cercana a Casares entre el

64. Ibidem, 289.

65. Е. P. Thompson (1981), 181.

66. R. Benitez Sánchez-Blanco (1982), 193-194.

67. D. García Hernán (1999), 235-236.

68. AHNOB, Sección Osuna, leg. 123-5, exp. 12.

69. L. del Mármol Carvajal (2015), 704; G. Pérez de Hita (1997), 315. 
duque y los insurrectos, representados por una persona de cada uno de los pueblos sublevados, junto con dos importantes personalidades: Alarabique ${ }^{70}$ y el Ataifar, "hombres de gran autoridad y por quien ellos se gobiernan" 71 . En el referido encuentro se habrían acercado ambas posturas, dando aquellos una serie de condiciones necesarias para posibilitar la reducción y pacificación de su pueblo, y que habrían sido enviadas a Felipe II para dirimirlas. Desconocemos, por la imprecisión cronística, la ubicación cronológica de este acontecimiento, más allá de la respuesta regia llegada a finales del mes de julio.

En dicha resolución se acordó que el día de Santiago volverían a reunirse ambas partes. No obstante, cuando una comitiva morisca se disponía a emprender el camino desde sus distintos lugares de habitación hasta la villa casareña fueron atacados por una cabalgada capitaneada por Alonso de Alarcón, capitán de Estepona. Este hecho, más allá de lo anecdótico, nos pone de relieve una interesante faceta de la región que merece ser analizada. Ya anotamos, como bien estudió M. Acién Almansa, el papel de frontera que durante el Bajo Medievo presentó la zona y su correlato en las actividades nobiliarias en su vertiente militar. Como ya han apuntado varios autores, tras la caída del reino nazarí de Granada en 1492, la antigua "frontera medieval" dio paso a una "nueva frontera" que, según Barrios Aguilera, no solo implica su traslado a la línea de costa, sino también una nueva interacción entre los sujetos presentes, propia de una nueva fase histórica $^{72}$. En esta línea, B. Vincent, basándose en la desproporción numérica entre la población musulmana y la cristianovieja hasta la rebelión morisca, reflexionó sobre la existencia de una compleja "frontera interior" en el reino granadino ${ }^{73}$.

En nuestro caso de estudio, en la segunda mitad del quinientos constatamos la continuidad de la situación fronteriza. Debemos considerar la permanencia de los moriscos en sus antiguos núcleos residenciales, rodeados en sus rebordes por núcleos urbanos -tanto interiores como de costa- habitados por los descendientes de los primeros repobladores. Como cabría esperar, la consideración de la inferioridad hacia los moriscos se manifestó en una curiosa actitud: las tierras de la Serranía de Ronda eran aún tomadas como una zona propicia para practicar incursiones o razias con

70. También denominado Arrabahe según las fuentes.

71. L. del Mármol Carvajal (2015), 704; D. Hurtado de Mendoza (1970), 376.

72. M. Barrios Aguilera (1997), 584.

73. B. VinCENT (1992), 109-114. 
el fin último de obtener beneficio sin necesidad alguna de declaración de guerra. Por ello, vemos una dilación de esquemas medievales que nos dan las notas de la convivencia cotidiana y relaciones entre moriscos y cristianos viejos en vísperas de la sublevación. Esto nos permite aproximarnos a la distancia de ambos colectivos, no solo en clave cultural, ideológica o identitaria, sino también geográfica. No en vano desde hace años se viene reclamando que una adecuada comprensión de la sociedad hispana y el devenir de los moriscos a corto y medio plazo pasa por aproximarnos a la historia local, rural y urbana y sus fuentes, pues nos dan las verdaderas bases de la realidad cotidiana del fenómeno morisco ${ }^{74}$.

Continuando con lo anterior, el duque no excluía más inoportunas correrías, y el día 28 pudo parlamentar con los representantes moriscos: "ayer llegaron aqui por la mañana los principales de ellos y truxeron de cada conçejo una o dos personas para asentar por si y por los demas de sus lugares lo que se acordase..." $" 75$. Resulta curioso, como se desprende de estas líneas, la estructura administrativa concejil existente en las comunidades de la región, eminentemente rural, y cómo esa comunidad morisca es capaz de cohesionarse en fórmulas representativas con vistas a un pactismo que excluya cualquier conflicto, a pesar de la existencia de tendencias heterodoxas como inmediatamente veremos.

En un principio presupusieron como condiciones inobjetables para la reducción pacífica la vuelta de los moriscos capturados en las primeras acciones y una solución factible al extenuante pago de las fardas -clara muestra de la crisis económica de los campesinos del reino en vísperas de la sublevación-, imposiciones que fueron rechazadas de lleno, y finalmente, desistidas en parte por los reclamantes ${ }^{76}$. Por ello, se estipuló un periodo de diez a doce días en el que los miembros del resto de la comunidad debían presentarse en la villa de Casares para confirmar ante escribano público su reducción y hacer entrega de sus armas como prueba y condición de su carácter pacífico ${ }^{77}$. En este periodo se procuraría la devolución de las mujeres y niños incautados en las primeras intervenciones, que se encontraban en distintas villas del reino de Sevilla (Écija, Carmona, Marchena y Arcos). Además, entraba en juego otra importante cuestión: la presencia de "turcos" entre los moriscos serranos, que a petición propia, solicitan el

74. R. Benítez Sánchez-Blanco (1996), 335-336.

75. AHNOB, Sección Osuna, C. 1635, D. 224, fol. 1r.

76. Ibidem.

77. Ibidem. 
flete de bergantines para la vuelta al norte de África. No podemos obviar que desde meses atrás esa "internacionalización" del conflicto se materializó en la Alpujarra, con la presencia de turcos y berberiscos. Esa realidad aparece también en el área estudiada, donde los contactos con la costa eran realmente sencillos -y estratégicos-, en todo el ámbito geográfico desde Marbella hasta Gibraltar.

No obstante, la ayuda del sultán otomano, a quien le correspondía la protección y ayuda a los moriscos granadinos por su condición de autoridad religiosa en el mundo islámico, se limitó a un plano más teórico ${ }^{78}$. En cuanto a Argel, su conversión en una república corsaria en época de la rebelión hizo que, más allá de infiltrar informadores y apoyar en ciertas ocasiones, sobre todo en época de Barbarroja, su intervención fuera testimonial a pesar del halo propagandístico con que las autoridades impregnaron la cuestión ${ }^{79}$.

Sin desviarnos en exceso de la cuestión central, en este intento de normalizar la situación se produjo un considerable trasiego de gentes para reducirse y entregar sus armas. En teoría la reducción implicaba la necesariedad de tal entrega, garantía de su condición pacífica, pero esta no fue algo unánime entre los reducidos. De hecho, el gran temor era que mantuvieran sus armas escondidas y, en realidad, siguieran entrañando un peligro violento ${ }^{80}$. Sin embargo, esta situación no debe relacionarse necesariamente con una actitud probélica, sino con una motivación económica. Las armas, en muchas ocasiones utensilios de labranza imprescindibles para las labores agrícolas con que subsistían, tenían un valor monetario intrínseco que sus poseedores perdían si procedían a su entrega. El propio duque era consciente de esta situación, que condicionaba una reducción efectiva e íntegra. Aunque se intentó la devolución en metálico por su venta en almoneda, fue algo nunca efectuado, condicionando, de entrada, estos cauces que habrían de llevar a la pacificación.

No obstante, no era este el único factor desestabilizador. Este idílico escenario entra en quiebra en cuanto desterramos de nuestro análisis la idea de una comunidad morisca homogénea. De hecho, las divisiones internas y las contradicciones de las posturas tomadas frente a los cristianos supusieron uno de los más acuciantes problemas de los moriscos de cara a afrontar el conflicto $^{81}$. Como bien ha estudiado V. Sánchez Ramos "un enfrentamiento

78. M. Á. de Bunes Ibarra (2004), 67.

79. Ibidem, 72-73.

80. L. del Mármol Carvajal (2015), 705.

81. A. Galán Sánchez (1993), 131. 
bélico extrema ideas quizás no tan claras en tiempos de paz" y, en este caso, el bando morisco no era un cuerpo compacto ${ }^{82}$. Todo lo contrario, siempre existieron varias opiniones respecto a las posturas ante el conflicto, en muchas ocasiones, radicalmente opuestas, pero tendentes al control de los resortes del poder del "estado morisco" ${ }^{83}$. En palabras del duque:

... no dexaran de venir [a reducirse] si no impide el recatamiento que an de tener de que no se les buelva a hazer alguna entrada como el otro dia o ser uno de los dos que aora manda mas entre ellos el Meliche, un ruin moro que fue el que hizo ahorcar a quatro veçinos de los que se enbiaron al principio a tratar de medio con ellos ${ }^{84}$.

Sin duda Mármol Carvajal fue el cronista que mejor apreció y mostró las diferencias existentes en el bando morisco, no solo a luz de los documentos moriscos que pudo analizar sino también a través de los testimonios orales que averiguó ${ }^{85}$.

Frente a las posturas pactistas por las que se estaba discurriendo por parte de un sector moderado, hegemónico numéricamente, se encontraban las actitudes más intransigentes, totalmente reacias a la pacificación y reducción. Esta línea, ideológicamente más integrista, estaba engrosada y liderada por los monfíes, bien conocidos por sus medios de acción más cruentos y violentos ${ }^{86}$. En el conflicto rondeño esta causa aparece enarbolada por un personaje en cierto modo enigmático, un monfí llamado el Melchi, con una importancia señera en el monfismo regional en un periodo que traspasa los horizontes cronológicos de nuestro estudio ${ }^{87}$.

Así, en un contexto de continuas vejaciones y actuaciones indebidas por parte de los cristianos viejos, cobró fuerza aquel sector disidente opuesto al desarmarse. El Melchi es el encargado de dar muerte a Arrabahe, figura erigida en el jefe opuesto a las tendencias violentas más extremistas, y que había conseguido la reducción del campo, junto al turco que poco antes pedía la embarcación de sus hombres al otro lado del Estrecho. En

82. V. SÁnchez Ramos (1999), 507.

83. Ibidem.

84. AHNOB, Sección Osuna, C. 1635, D. 223, fol. 2r.

85. J. Castillo Fernández (2015), 32.

86. V. Sánchez Ramos (1999), 512.

87. Son varias las denominaciones que recibe este personaje. Pérez de Hita lo refiere como Malique. G. Pérez de Hita (1997), 314. Por su parte, Mármol Carvajal como el Melchi, forma que parece la más usada. L. Del Mármol Carvajal (2015), 705. 
cuestión de días todos los planes del duque se derrumbaban a la par que se vislumbraba un horizonte armado no muy lejano. En boca de Ponce de León: "vista la voluntad de este ruyn moro y de los que están cabe el se entienda que aunque vengan algunos no dexara de quedar numero de gente que haga el mismo daño en esta tierra que hazia antes si no se pone remedio en ello con brevedad"88. La situación no dejaba lugar a dudas: debían preparar la guerra. Entonces el duque de Arcos se percata de la necesidad de emprender un conflicto armado, opción a la que en primera instancia prefirió no recurrir por los motivos expuestos. Además, fue ganando peso la idea de la expulsión de la totalidad de los moriscos frente a las tentativas pacifistas de Ponce de León ${ }^{89}$.

En estos instantes se dio en algunas zonas del reino, sobre todo montañosas, un auténtico "renacimiento serrano", constatado documentalmente incluso en la región rondeña, en el que se luchó, al calor de la lucha y la cohesión ideológica -en ocasiones fanatizada-, por vitalizar los ritos moriscos, en muchos casos edulcorados por la aculturación ${ }^{90}$.

\subsection{La resistencia armada y la preparación de la guerra (agosto- septiembre de 1570)}

Si la resistencia liderada por el Melchi ya era una cuestión grave a erradicar, diversas noticias como los contactos con los rebeldes de la Alpujarra -aprovisionadores de pólvora-, la ocupación de la sierra de Arboto o el reforzamiento del fuerte de Calaluz no hacían sino inquietar al duque.

La preparación de una guerra de tales características, no tanto por magnitud, sino por especificidad, era una cuestión harto delicada por varias cuestiones. En primer lugar, necesitaban juntar un ejército consistente y, como ocurrió en la primera incursión, las tropas a las que se podía recurrir, exceptuando las aportaciones en hombres propias del duque, eran concejiles. Más allá de la nula formación y carencia de equipamiento, su periodo de lucha oscila entre los doce y los quince días, para inmediatamente abandonar su cometido si no tienen garantizado el pago de su continuación ${ }^{91}$. A los problemas logísticos le sumaban, de cara a la planificación, el hecho de que la población morisca dispersa era totalmente desconocida.

88. AHNOB, Sección Osuna, C. 1635, D. 227, fol. 1r.

89. R. Benítez Sánchez-Blanco (1982), 195.

90. M. Barrios Aguilera (2000), 371.

91. AHNOB, Sección Osuna, C. 1635, D. 223. 
En segundo lugar, la cuestión numérica de las tropas. Como cabría esperar las aportaciones concejiles de Ronda estaban previstas, pero su contribución distaba mucho de alcanzar la cuantía mínima estimada para poder intervenir. Por ello, era necesario el apoyo de los corregimientos cercanos, reacios a prestar a sus vecinos, que, por lo demás, presentan la misma problemática de la duración y el pago.

En tercer lugar, debemos matizar una cuestión alimenticia. Tradicionalmente los conflictos son estudiados desde una óptica militar, que en ningún caso podemos olvidar, pero la complejidad de los fenómenos históricos hace que tampoco podamos descuidar el evidente correlato social $-\mathrm{y}$ de vida cotidiana- igualmente presente. En este sentido, la entrada en acción de los soldados concejiles exigía la previsión de las vituallas alimenticias de los mismos -"el trigo que uviere de juntar para hazer arina" ${ }^{2}$, , que deben ser asumidas por las poblaciones circundantes. Sin embargo, el municipio rondeño no parece tener la capacidad disponible necesaria, ni tampoco es factible su traslado por la sierra, sino por el $\operatorname{mar}^{93}$. Además, surge la cuestión de la financiación de la guerra, asunto totalmente desconocido a nivel general. Sin adentrarnos en una temática que merecería una compleja investigación particular, para el caso rondeño podemos atisbar que se trató de una sufragación mixta entre los corregimientos implicados, la Casa de Arcos y la Monarquía, en una coyuntura en que nobleza y Corona se intentan eximir mutuamente de los más acuciantes gastos.

Por si fuera poco tampoco podemos dejar de tener en cuenta el carácter residual de este conflicto, relegado en importancia en las postrimerías de la guerra en las Alpujarras, hasta el punto de que en estos momentos, cuando se está intentando preparar la intervención armada, son reclamados soldados del corregimiento de Ronda para esa zona granadina por parte de don Juan de Austria ${ }^{94}$. El duque era claro: "ymporta allanar con brevedad esta tierra y que mientras mas se tardare en hazello avra mayores yncombenientes...una de las cosas que mas ymportan acabar en este reyno es esto de aqui..." 95 .

Por el lado morisco las dificultades también estaban a la orden del día. No solo tenían en su contra las divergencias ideológicas en torno a la política a tomar, sino que la mayoría de ellos, exceptuando los monfíes, carecían de conocimientos bélicos de cara a organizar contingentes efecti-

92. AHNOB, Sección Osuna, C. 1635, D. 235, fol. 2r.

93. AHNOB, Sección Osuna, C. 1635, D. 223.

94. AHNOB, Sección Osuna, C. 1635, D. 231.

95. Ibidem. 
vos; contaban con escasas armas (excluyendo los navíos y la caballería); y finalmente, como antes decíamos, el apoyo islámico exterior fue parco ${ }^{96}$. De esta forma, los moriscos únicamente tuvieron de aliados el conocimiento y manejo de la geografía así como los apoyos mutuos entre ellos.

Si la cuestión ya era naturalmente difícil, los ánimos de los moriscos, una gran mayoría, bajo la categoría de reducidos, se ven afectados por las continuas actuaciones indebidas y vejaciones de los cristianos viejos, condenadas y castigadas por el rey ${ }^{97}$. Desde bandoleros profesionales, soldados en torno al conocido Antón García el Manco, o los vecinos de las comarcas circundantes, se entregan al robo y a la esclavitud morisca ${ }^{98}$ :

Esta mañana tuve nueva como muchos de los que abian rendido las armas y estavan reducidos en sus lugares se an buelto al canpo con los rebeldes y para decir la verdad a V.M paresçeme que no han dexado de tener razon para hazello (...) mataron numero dellos y otros ataron y llevaron a un lugar la tierra adentro por esclavos...99.

En estos momentos aún continuaban las reducciones voluntarias en Casares, pero allí no eran mejor recibidos, donde el problema era velar por su seguridad para que "desde la puerta por donde entravan hasta mi presencia no los matasen a pedradas y a palos" ${ }^{100}$. Así, podemos considerar a los moriscos de la Serranía de Ronda como un colectivo pacífico, forzados a rebelarse por cuestiones externas e incluso, en una gran mayoría, son favorables hacia una vuelta a la normalidad anterior, pero son en última instancia las actitudes de los cristianos viejos en amplio sentido los que fuerzan a preparar la guerra. En suma, si bien se condena e intenta juzgar a los cabecillas de las razias con fines esclavistas, lo cierto es que, $a$ posteriori, la globalidad de los moriscos tornados violentos con motivos bien justificados son tomados como acérrimos enemigos cuyo objetivo es "matar dellos los que pudiéremos sin perder tiempo" 101.

Mientras Juan de Espuche quedaría a cargo de la vigilancia del fuerte de Calaluz, cada vez más preocupante por los contactos que desde allí tenían con sus correligionarios de Sierra Bermeja, el duque partía hacia

96. A. Galán SÁnchez (1993), 130-131.

97. AHNOB, Sección Torrelaguna, C. 250, D. 20.

98. R. Benítez Sánchez-Blanco (1982), 188; AHNOB, Sección Torrelaguna, C. 250, D. 17.

99. AHNOB, Sección Osuna, C. 1635, D. 236, fol. 1r.

100. Ibidem, fol. $1 \mathrm{v}$.

101. AHNOB, Sección Osuna, C. 1635, D. 242, fol. 2r. 
Ronda $^{102}$. Allí esperaba reunir un sólido ejército. Para ello, Felipe II pidió a las ciudades de Málaga y Jerez la aportación de cuantas tropas concejiles estuviesen en su mano. La contribución del corregimiento Ronda-Marbella era más que evidente; y Gibraltar, por su parte, apoyaría la logística del conflicto con sus posibilidades marítimas ${ }^{103}$. En un principio no se excluye la posibilidad de gentes venidas de las ciudades de Alcalá, Antequera, Alhama y Loja ${ }^{104}$. Además, el monarca organiza la composición señorial de las tropas, que correrían a su cargo. Esta se concretó en los hombres proporcionados por el duque de Alcalá, el marqués de Priego, de Estepa y de Ardales ${ }^{105}$. Junto a ellos, don Luis contactó con el duque de Medina y de Osuna, a sumar su propio aporte, el de la Casa de $A r \cos ^{106}$.

Según las estimaciones del duque los efectivos procedentes de Ronda podían ascender perfectamente a las cuatro mil personas, pero insuficientes "vista la dispusicion donde de la tierra donde estan los moros" 107. Máxime si tenemos en cuenta que el plan estratégico consistiría en la ocupación de todas las salidas posibles de los puntos de altura atacados para evitar la dispersión morisca por la sierra y la concentración en puntos concretos, caso del fuerte de Calaluz y, sobre todo, de Arboto, el otro gran bastión morisco en las proximidades de Istán. Su importancia era vital en tanto que localizado en uno de los puntos más altos de la sierra, se convirtió en una "auténtica reserva de alimentos y armamentos" que conectaba con el resto de las zonas rebeldes, con una espectacular visual de la zona y de la costa mediterránea; ahora, en tales alturas tampoco faltaron de aprovisionamiento, alimentando el referido monfismo ${ }^{108}$.

Al parecer, este último núcleo serrano aglutinaba a todos los descontentos de su entorno, que, progresivamente, se iban incrementando. No es de extrañar este aspecto si atendemos a los raptos de mujeres e hijos de lugares reducidos, como ocurre en estos instantes en el entorno de Marbe1la, Cartajima y Parauta, o los desmanes de idéntica índole cometidos por los soldados en la zona de Montejaque, en palabras del duque: "fue la de orden que paso tan grande que tenemos aqui entendido que no avra quedado

102. AHNOB, Sección Osuna, C. 1635, D. 231; D, 235.

103. AHNOB, Sección Torrelaguna, C. 250, D. 12.

104. AHNOB, Sección Osuna, C. 1635, D. 235, fol. 2r.

105. AHNOB, Sección Torrelaguna, C. 250, D. 13.

106. AHNOB, Sección Osuna, C. 1635, D. 235, fols. 1v-2r.

107. AHNOB, Sección Osuna, C. 1635, D. 240, fol. 1r.

108. C. Urbaneja Ortiz (2008), 539. 
ninguno de los que se reduxeron" ${ }^{109}$. Todos coincidían en la necesidad de un castigo ejemplar que evitara la propagación de tan perjudiciales prácticas para el devenir del conflicto ${ }^{110}$.

Con el horizonte más enturbiado el duque tuvo que prescindir de las tropas de Sevilla, aunque las compensó con dos mil ducados destinados al socorro de las compañías ${ }^{111}$. Contando con todos los aportes concejiles - excepto las ciudades del entorno granadino, Antequera y Jerez-, y señoriales y la estrategia planteada, el duque partió el 16 de septiembre rumbo al sitio de Arboto: era de iure el comienzo de la guerra ${ }^{112}$.

\subsection{La guerra: los hechos (septiembre de 1570)}

En este complejo entramado no podemos perder de vista que la propia serranía no era un conjunto uniforme ni indiferenciado en lo geográfico, pero tampoco en lo social. Es más, si los acontecimientos en Casares son los que incitarán a la preparación de la guerra, esta será a lo largo del conflicto una zona pacífica en la que no se vuelva a intervenir bajo la consideración, a pesar de todo, de residencia de moriscos reducidos. Sin embargo, sí habrá una focalización concreta, pues la atención iba centrada hacia aquellas áreas montañosas donde hubiera moriscos violentos, pero no las zonas campesinas llanas. De hecho, en todo momento la intención del duque es "allanar la tierra", enfocando sus objetivos en la montaña, con el papel allí desempeñado por los monfíes, los únicos que, a la postre, tenían experiencia y conocimientos bélicos para emprender una guerra de guerrillas ${ }^{113}$. Paralelamente, Ponce de León deja en Ronda a su hijo, Lope Zapata, encargado de la gestión de los moriscos que allí fuesen a reducirse. Pero, a fin de cuentas, esta reducción se vio seriamente limitada por los excesos cometidos por los cristianos viejos ${ }^{114}$.

El duque de Arcos pasó a dirigir las cinco compañías reclutadas en Ronda, cuyos gastos corrían a cargo de la Corona. Tres de ellas estaban capitaneadas por Pedro Bermúdez - corregidor rondeño- y las dos restantes por Jorge Morejón y Gaspar de Alarcón. Días más tarde llegarían a

109. AHNOB, Sección Osuna, C. 1635, D. 241, fol. 1v.

110. AHNOB, Sección Osuna, C. 1635, D. 231, fol. 1r.

111. AHNOB, Sección Torrelaguna, C. 250, D. 10.

112. L. del Mármol Carvajal (2015), 709-710. A partir de mediados de septiembre vuelven las referencias cronísticas por parte de Mármol Carvajal y Hurtado de Mendoza.

113. A. Galán Sánchez (1993), 131.

114. L. del Mármol Carvajal (2015), 710. 
Istán-Arboto las gentes de Málaga bajo las órdenes de Arévalo de Zuazo, corregidor malacitano ${ }^{115}$. Junto a ellas Juan de Espuche y Pedro de Mendoza figuran como en consejeros y máximos ayudantes del duque.

En el entorno de la llamada sierra de Arboto, y aún sin contar con la ayuda malagueña, fue necesario tomar el control de una zona próxima a la sierra, cuya importancia era clave para poder emprender las acciones ulteriores ${ }^{116}$. Una vez tomada, y concluida la llegada del resto de contingentes, las operaciones podían empezar: era el 21 de septiembre. El aporte de las tropas concejiles malagueñas fue determinante ante las escasas tropas que, al fin y al cabo, habían reclutado en Ronda ${ }^{117}$.

Todos los esfuerzos debían concentrarse en la toma del fuerte de Arboto. Si algo tenían claro las tropas era que la enrevesada geografía constituía una ventaja que explotaban bien los moriscos. A sabiendas de que los refugios se encontraban en las partes más encumbradas de las crestas montañosas, el planteamiento más lógico era someter las zonas bajas, para ir progresivamente escalando en el área de refugio neoconverso. La expedición fue capitaneada por Pedro de Mendoza, aunque no obtuvo inicialmente lo previsto.

El referido capitán, dotado de unos dos mil arcabuceros, se topó con un nutrido grupo de moriscos que comenzó a atacar. Un rápido refuerzo de las tropas permitió el inmediato apaciguamiento de la zona, pero desde ambos flancos se ansió más, lo que dio lugar a una escaramuza. A juicio de Ponce de León, los moriscos huían a la sierra con el fin de buscar el apoyo de otros refugiados en puntos más altos. Una vez ascendida la montaña con las tropas tras de sí podrían enfrentarse a ellos sin problemas. En aquel punto la superioridad estaría del lado morisco mientras que lo escarpado del lugar no permitiría el socorro de las tropas. Ante este panorama, don Luis envió a dos capitanes para dar la orden de abortar la operación y recoger a las dos cuadrillas ${ }^{118}$. El problema fue la rebeldía de unas tropas que, animadas por los refuerzos del duque, hicieron oídos sordos a las órdenes reiteradas de retorno y de peligro de la operación. El duque optó por aumentar el número de soldados con tres contingentes más dirigidos

115. AHNOB, Sección Osuna, C. 1635, D. 250, fol. 1.

116. L. del Mármol Carvajal (2015), 710.

117. El aporte se concretó en 1500 arcabuceros y 110 caballos, si bien Mármol altera sensiblemente las cifras. AHNOB, Sección Torrelaguna, C. 250, D. 22; L. DEL MÁrmOL Carvajal (2015), 710.

118. AHNOB, Sección Osuna, C. 1635, D. 260. 
por Pedro Bermúdez, Juan de Espuche, y por el propio duque. Mientras tanto Arévalo de Zuazo quedaría en las bases del campo ${ }^{119}$.

El cambio improvisado y forzado de estrategia también lo encontramos en el lado morisco. Ante el ingente aumento de los efectivos optan por la huida hasta llegar al fuerte por la parte del Picacho de Marbella. Este quedó tomado al ocaso de la tarde, mientras una parte de las tropas continuó la persecución de los moriscos hasta río Verde, donde fueron capturados y esclavizados más de cuatrocientos ${ }^{120}$. Al mismo tiempo, al atardecer, unos mil quinientos hombres fueron mandados desde el fuerte a rastrear la zona por la que habían huido. Constataron que el elevado número de huidos se dispersó por los lugares reducidos del Havaral -lo que suponía un grave problema-, junto a Tolox, Monda y Sierra Bermeja ${ }^{121}$.

La operación había dejado capturado el ansiado fuerte, si bien no con todo el provecho que se hubiese podido obtener de haber ejecutado una operación de forma disciplinada ${ }^{122}$. Las gentes de Málaga fueron licenciadas y el duque toma la idea de instalar un presidio en la zona para garantizar su seguridad ${ }^{123}$.

Quizás, lo más importante de la actuación es la primera conclusión que saca el Duque: "por la aspereza de la tierra y la dispusiçion de ella parece que con dificultad se podian çercar los moros que avia para degollarlos todos" 124 . El contacto primerizo con la zona le pone de manifiesto que la tesitura exige una forma de actuar concreta, condicionada por la geografía, pero difícilmente ejecutable. La dispersión de los moriscos por la sierra, con su gran amplitud, hace imposible controlarlos al completo. Por tanto, momentáneamente, no queda más solución que emprender una campaña de búsqueda de moriscos para abatirlos y disminuir su número.

Era de suponer que los nuevos nidos moriscos los encontrarían en la zona de Istán, Ojén y Monda. El duque manda a cuatro cuadrillas de unos

119. Ibidem.

120. Pérez de Hita, a grandes rasgos, coincide en su relato con lo aportado por las fuentes documentales; eso sí con su habitual discurso heroico y de semblanza. Sin embargo, llama la atención el hecho de que tras la explicada operación, afirme la muerte del Malique. Con su desaparición y la descoordinación de sus gentes, la guerra habría terminado en esta zona, dándose con una considerable huida hacia África. Todo lo contrario, la desestabilización de la zona se dilataría aún en el tiempo como nos muestran el resto de fuentes analizadas. G. PÉrez de Hita (1997), 316-317.

121. AHNOB, Sección Osuna, C. 1635, D. 260.

122. Ibidem.

123. L. del Mármol Carvajal (2015), 712.

124. AHNOB, Sección Osuna, C. 1635, D. 259. 
cien tiradores que conociesen la tierra para atacar esos puntos ${ }^{125}$. Don Luis les acompañaría por la zona de Istán. Estas expediciones, más allá de capturar una treintena de esclavos, reconocer el peligro de Monda, y destruir algún que otro bergantín rumbo a Berbería, ponen de manifiesto al duque que es inútil el gasto invertido en tropas y vituallas para combatir a los moriscos en un medio tan hostil. Ahora sí plantea al rey la necesidad de un cambio de estrategia:

para lo que toca al servicio de V. M. y acabar de allanar todo esto son dos cosas; la una dexar dos o tres presidios con gente que pudiese salir dellos a acortallos los pasos y no dexallos juntar en ninguna parte quitandoles las vituallas y otras comodidades (...). La otra es que V.M mandase que no se quedase ningun morisco de los reduzidos en toda la tierra porque entre tanto que ellos estuviesen en ella no se puede acabar de allanar... ${ }^{126}$.

Mármol Carvajal añade la operación del capitán Francisco Ascanio en la tierra de Monda y Ojén, cuya actuación habría precisado la vuelta de Arévalo de Zuazo con sus hombres y Pedro Bermúdez, entre otros ${ }^{127}$, y al respecto refiere la documentación conservada: "andar por campo formado tras estos es gastar tiempo sin provecho, porque en descubriendo golpe de gente en que reconocen ventaja no esperan a pelear sino vanse de una sierra a otra" 128 . Si a ello sumamos que los cuerpos concejiles abandonaban por la necesidad de atender sus labores de siembra, se entiende que el duque optara por licenciar a la mayoría de las compañías y volver a Ronda ${ }^{129}$.

\subsection{La expulsión de los moriscos y las últimas acciones (octubre- noviembre de 1570)}

En estos instantes ciertos moriscos reflexionaron sobre la situación y postularon a Carlos de Villegas en Benahavís una rendición, situación que, al igual, se produjo en Montejaque ${ }^{130}$. El duque, con recelo, aceptó

125. L. del Mármol Carvajal (2015), 712.

126. AHNOB, Sección Osuna, C. 1635, D. 260, fol. 3r.

127. L. del Mármol Carvajal (2015), 713.

128. AHNOB, Sección Osuna, C. 1635, D. 265, fol. 1v-2r.

129. Las ricas aportaciones de Mármol Carvajal finalizan a comienzos de octubre con la vuelta del duque a Ronda, contando a partir de entonces únicamente con lo aportado por la documentación epistolar.

130. C. Urbaneja Ortiz (2008), 547. 
un encuentro para acercar posturas, previa entrega de las armas y aceptación incondicional de la derrota, algo que, a priori, aparece facilitado por la escasez de alimentos y dificultades de subsistencia por parte de los moriscos refugiados en la sierra y la actitud depredatoria de los grupos de cristianos viejos que recorren la zona ${ }^{131}$. Ahora, los sujetos moriscos tras tales anhelos no eran sino una minoría que iniciaría, en complejas circunstancias, un proceso de reducción prolongado casi un año ${ }^{132}$. Mientras tanto la rebelión proseguía.

A comienzos del mes de octubre, y con apenas una quincena de días combatiendo, el duque decide no hacer frente a lo que era una guerra de guerrillas, y "por no hallar moro con quien pelear", vuelve a Ronda ${ }^{133}$. Desde allí, de un lado, dirigirá la preparación de los presidios y la expulsión de los moriscos reducidos, y de otro, luchará contra las actuaciones de los cristianos viejos, que volvían a acechar.

La tipología de acciones cometidas por estos era variada formal y geográficamente: desde las vejaciones practicadas a los reducidos del Havaral, los robos en Montejaque y Algotocín, la esclavitud de moriscas en Istán, o las actuaciones de vecinos de Jimena, Gaucín y Casares sobre Cartajima ${ }^{134}$. El castigo de tales imprudencias debía ser controlado y penado severamente, sobre todo en un momento en que el rey había ratificado la decisión de expulsar a los moriscos del reino de Granada. Ya el propio duque, claramente subordinado a la figura de don Juan de Austria, cabeza rectora de la operación, preparaba la entrada en la sierra. No se debían incrementar los descontentos para evitar aumentar el número de rebeldes.

Por otra parte, tanto para la ejecución de la expulsión como para la instalación de los presidios era imprescindible la recomposición de las compañías despedidas, pero el problema era idéntico a las semanas anteriores: gran parte de los componentes estaban ocupados en sus tareas de sementera ${ }^{135}$. Esto hace volver a recuperar las compañías anteriores -de primacía señorial- que ya conocen la zona y la estrategia. Este nuevo reclutamiento sucede de forma lenta, lo que provoca el retraso de la expulsión hasta principios de noviembre, cuando sería ejecutada.

131. Ibidem, 548-549.

132. Ibidem, 550 .

133. AHNOB, Sección Osuna, C. 1635, D. 269, fol. 1r.

134. AHNOB, Sección Osuna, C. 1635, D. 270, fol. 1r; D. 277, fol. 2v.

135. AHNOB, Sección Osuna, C. 1635, D. 270, fol. 1r. 


\section{CONCLUSIÓN}

El conflicto rondeño se presenta como un escenario idiosincrático para el análisis de una región ciertamente pacífica en sus inicios. Podemos hablar de una guerra que emerge de forma forzada, incitada por agentes externos: la decisión regia de expulsar a los moriscos de paces del reino de Granada, materializada en la fatídica operación de Antonio de Luna en la Serranía de Ronda. Solo su intervención con unas depredatorias tropas concejiles entregadas al robo y la esclavitud fuerza a un grupo de moriscos a radicalizarse. Si bien existía un nutrido monfismo en la serranía, el grueso de la comunidad, bajo inevitables diferencias ideológicas, se trataba de un colectivo pacífico. Carácter pacífico sancionado tras estos hechos, pues el grueso de los moriscos de las zonas puramente rurales, tras unas demandas al rey que finalmente rebajan, se reducen voluntariamente. Solo será la continuación de esa actitud depredatoria por parte de los cristianos viejos de los núcleos circundantes, en sus diversos grupos y manifestaciones, lo que obligue a "echarse al monte" a aquella minoría más intransigente, llevando sus apoyos tras de sí. Así, se trata de una guerra iniciada, en principio, con la intención de expulsar a los moriscos de paces, algo a enfatizar, pues solo el devenir de los acontecimientos hará que el objetivo se desvíe hacia los monfíes radicalizados en la sierra por estas intenciones iniciales.

Todo ello nos permite hablar de una consideración de inferioridad por parte de los cristianos viejos hacia los moriscos, vistos por sus vecinos no serranos como una comunidad, hacinada geográficamente en los valles intramontañosos del Genal y Guadiaro, a la que esclavizar y robar; y por parte de la Corona, como un pueblo a expulsar sin distinciones, incluso a aquellos con declaración escrita de paz, reducción y entrega de armas. Solo el duque de Arcos, tras la operación de Antonio de Luna, se opone a la pregonada expulsión, tan deseada y defendida con ahínco, a tenor de la documentación consultada, por Felipe II y don Juan de Austria. Eso sí, por un interés personal, partidista y de fondo pecuniario, no en aras de los moriscos y mejoría como colectivo o defensa de ciertos derechos. Tras el fracaso de las negociaciones, comenzó la guerra.

Bajo estas premisas, los moriscos, como colectivo indefenso y carente de grandes medios con los que hacer la guerra, condicionan el desarrollo de una "guerra de guerrillas" en que la superioridad bélica de los cristianos -con todas sus dificultades analizadas- no alcanza el gran arma que supone el dominio y conocimiento de la tierra, cobijo y fortaleza de los moriscos decididos a no reducirse y/o hacer la guerra al monarca. 
A fin de cuentas, esta guerra consistió por parte de los moriscos en una desesperada huida sierra tras sierra, intentando evitar un inexorable destino que las acciones regias no dejaban de sancionar. Y, a la postre, el conflicto fue en vano, pues las operaciones se limitaron a una serie de cazas, generalmente infructuosas, a excepción del hallazgo ocasional de auténticos botines humanos, naturalmente esclavizados. Este esquema, invariable desde que el duque penetra en el corazón de la serranía, lleva a las autoridades del conflicto a percibir la ineficacia de una estrategia, que más allá de consumir tiempo, vitualla y soldados, no resulta efectiva. El problema es que en tales circunstancias tampoco otra metodología bélica resultaría eficaz. La propia lógica del conflicto había hecho necesario reducir a componentes meramente testimoniales las aportaciones de caballería y engrosar las filas de infantes y, sobre todo, arcabuceros. Por ello, el objetivo de limpiar la tierra resultó ser una quimera que solo acarreó muerte, destrucción y numerosos gastos tanto al rey, a la nobleza imbricada en el conflicto, como a los concejos colaboradores.

Al final de la guerra, una guerra corta por sus propias circunstancias y de una saca totalmente simbólica respecto al número real de moriscos que habitaban la zona, la sierra no solo seguía plagada de moriscos, sino de moriscos tornados en auténticos monfíes, entregados al robo y la violencia como medio de sobrevivir refugiados en un medio que le es hostil.

Mientras se iniciaba esta nueva etapa protagonizada por la repoblación, un cuantioso colectivo morisco seguía enraizado en sus tierras, traspasando incluso la expulsión de 1609-1612, pues las diversas noticias inquisitoriales con que contamos nos muestran unas pervivencias más allá de estos momentos.

\section{BIBILIOGRAFÍA FINAL}

Benítez Sánchez-Blanco, Rafael (1974), “Guerra y sociedad. Málaga y los niños moriscos cautivos, 1569”, Estudis, 3, pp. 31-54.

- (1982), Moriscos y cristianos en el Condado de Casares, Diputación Provincial, Córdoba.

- (1996), "Las relaciones moriscos-cristianos viejos: entre la asimilación y el rechazo", en A. Mestre Sanchís y E. Giménez López, Exilios y disidencias en la España moderna, Universidad, Alicante, pp. 335-346.

- (2010), "El cautiverio de los moriscos", Manuscrits, 28, pp. 19-43.

Barrios Aguilera, Manuel (1997), "La nueva frontera. El Reino de Granada ante el mundo islámico en el siglo XVI”, en P. Segura Artero (coord.), Actas del Congreso La frontera oriental nazarí como sujeto histórico (S. XIII-XVI), Instituto de Estudios Almerienses, Almería, pp. 583-612. 
- (2007), La convivencia negada. Historia de los moriscos del Reino de Granada, Comares, Granada.

- (2000), "Religiosidad y vida cotidiana de los moriscos" en M. BARrios AguilerA (ed.), Historia del Reino de Granada II. La etapa morisca y la repoblación (1502-1630), Universidad-El legado andalusí, Granada, pp. 357-433.

Bravo Caro, Juan Jesús (1991), "Poblaciones moriscas de Málaga en el siglo XVI (1568-1571)", Baetica. Estudios de Arte, Geografia e Historia, 13, pp. $217-226$.

- (1998a), "Frontera y repoblación: una coyuntura crítica tras la guerra de las Alpujarras", Chronica Nova, 25, pp. 173-211.

— (1998b), "Los esclavos en Andalucía oriental durante la época de Felipe II", en J. Martínez Millán (dir.), Felipe II (1527-1598). Europa y la Monarquía Católica. Economía, Hacienda y Sociedad, t. 2, Parteluz, Madrid, pp. 133-164.

Bravo Caro, Juan Jesús e Ybañez Worboys, Pilar (2018), "Paisajes moriscos: cultura, identidad y economía”, en E. Ortega Arjonilla (coord.), El paisaje: percepciones interdisciplinares desde las humanidades, Comares, Granada, pp. 69-78.

Bunes Ibarra, Miguel Ángel de (2004), "El Imperio otomano y el reino de Granada”, en M. Barrios Aguilera y A. Galán SÁnchez (eds.), La historia del Reino de Granada a debate. Viejos y nuevos temas. Perspectivas de estudio, Diputación Provincial, Málaga, pp. 65-76.

Cabrillana Ciézar, Nicolás (1990), "Los despoblados de la provincia de Málaga tras la expulsión de los moriscos (1570-1600)", Mainake, 11-12, pp. 251-266.

Cardaillac, Louis (1979), Moriscos y cristianos. Un enfrentamiento polémico (1492-1640), Fondo de Cultura Económica, México D. F.

Caro Baroja, Julio (2010), Los moriscos del Reino de Granada, Alianza, Madrid.

Domínguez Ortiz, Antonio y Vincent, Bernard (1978), Historia de los moriscos. Vida y tragedia de una minoría, Biblioteca de la Revista de Occidente, Madrid.

Galán Sánchez, Ángel (1982), "Notas para el estudio del origen de la cuestión morisca las bases socio-económicas, el obispado de Málaga (1500-1515)", Historia. Instituciones. Documentos, 9, pp. 273-326.

- (1991), "Introducción”, en L. Del Marmol Carvajal, Rebelión y castigo de los moriscos, Arguval, Málaga, pp. 7-28.

- (1993), "Turcos y moriscos en la Rebelión de las Alpujarras: algunas notas sobre la Guerra de Granada de 1568-1570”, en E. Cruces Blanco (coord.), La organización militar en los siglos XV y XVI: actas de las II Jornadas Nacionales de Historia Militar, Universidad de Cádiz-Diputación de Sevilla, Málaga, pp. 129-136.

Galán Sánchez, Ángel y Peinado Santaella, Rafael Gerardo (1997), Hacienda regia y población en el Reino de Granada: la geografía morisca a comienzos del siglo XVI, Universidad, Granada.

García Hernán, David (2000), "La función militar de la nobleza en los orígenes de la España Moderna", Gladius. Estudios sobre armas antiguas, armamento, arte militar y vida cultural en Oriente y Occidente, 20, pp. 285-300. 
Gil SAnjuÁn, Joaquín (1979), “La inquisición de Granada. Visita a Málaga y su comarca en 1568", Baetica. Estudios de Arte, Geografía e Historia, 1, pp. 313-336.

- (1991), "Disidentes y marginados de la Serranía de Ronda en el tránsito a los tiempos modernos", Baetica. Estudios de Arte, Geografía e Historia, 13, pp. 227-239.

- (1997), "Ginés Pérez de Hita y las rebeliones moriscas malagueñas", Baetica. Estudios de Arte, Geografía e Historia, 19, pp. 121-134.

Jiménez Estrella, Antonio (2004), Poder, ejército y gobierno en el siglo XVI. La Capitanía General del reino de Granada y sus agentes, Universidad, Granada.

- (2009), "Las milicias en Castilla: evolución y proyección social de un modelo de defensa alternativo al ejército de los Austrias", en J. J. RuIz IBÁÑEZ (ed.), Las milicias del rey de España. Sociedad, política e identidad en las Monarquías Ibéricas, Fondo de Cultura Económica, Madrid, pp. 72-103.

López De Coca Castañer, José Enrique (1993-1994), “La «conversión general» en el obispado de Málaga”, Chronica Nova, 21, pp. 191-237.

- (1996), "La «conversión general» del reino de Granada", en E. SARASA SÁnchez [coord.], Fernando II de Aragón, el rey Católico, Institución Fernando el Católico, Zaragoza, pp. 519-538.

López García, Esteban (2014-2015), "El Havaral de Ronda en los últimos años de la etapa morisca: 1560-1570", Takurunna, 4-5, pp.185-236.

Martínez Enamorado, Virgilio y Castillo Rodríguez, José Antonio (2015), “Allí donde la gente de guerra fue vencida. Una propuesta de identificación para el lugar de la rota de Calaluz", en V. Martínez Enamorado y J. A. Castillo Rodríguez (coords.), El fin de al-Andalus en la Serranía de Ronda, Editorial La Serranía, Ronda, pp. 63-86.

Martínez Enamorado, Virgilio y Chavarría Vargas, José Antonio (2010), Toponimia mayor de la Serranía de Ronda, Editorial La Serranía, Ronda.

Martín CAsares, Aurelia (1998), "Esclavitud y mentalidad: la población esclava de Granada a lo largo del siglo XVI", Chronica Nova, 25, pp. 337-348.

Pereiro Barbero, Presentación (1985), “Absolutismo, ejército y privilegios locales", Baetica. Estudios de Arte, Geografía e Historia, 8, pp. 367-376.

Pérez Boyero, Enrique (1997), Moriscos y cristianos en los señoríos del reino de Granada (1490-1568), Universidad, Granada.

Pérez De Colosía Rodríguez, M. a Isabel (1986), "Visita inquisitorial de 1560 por tierras malagueñas", Baetica. Estudios de Arte, Geografía e Historia, 9, pp. 331-345.

RABASCO VAldÉs, José Manuel (1975), "Dos aspectos de la esclavitud morisca. Málaga, 1569”, en Homenaje al Dr. D. Juan Reglà Campistol, vol. I, Universidad, Valencia, pp. 293-302.

Rodríguez Martínez, Francisco (1977), La Serranía de Ronda. Estudio geográfico, Confederación Española de Cajas de Ahorros, Málaga. 
Ruiz Ibáñez, José Javier y Vincent, Bernard (2007), Los siglos XVI-XVII. Política y sociedad, Síntesis, Madrid.

Ruiz Povedano, José María (2018), Málaga, de musulmana a cristiana. La transformación de la ciudad a finales de la Edad Media, Universidad, Granada.

SÁnchez Ramos, Valeriano (2000), "La Guerra de las Alpujarras (1568-1570)", en M. Barrios Aguilera, (ed.), Historia del Reino de Granada II. La época morisca y la repoblación (1502-1630), Universidad-El legado andalusí, Granada, pp. 507-542.

- (1995), "Repoblación y defensa en el reino de Granada: campesinos-soldados y soldados-campesinos", Chronica Nova, 22, pp. 357-388.

- (1999), "La guerra dentro de la guerra: los bandos moriscos en el alzamiento de las Alpujarras", en VII Simposio Internacional de Mudejarismo, Instituto de Estudios Turolenses-Centro de Estudios Mudéjares, Teruel, pp. 507-520.

Siles Guerrero, Francisco (2011), "De alquerías medievales a despoblados modernos. Evolución administrativa y socioeconómica de los despoblados del Valle del Genal (siglos XV al XVIII)", Takurunna, 1, pp. 203-232.

Suberbiola Martínez, Jesús (1985), "La ordenación parroquial malacitana de 1505 y su reformación”, Baetica. Estudios de Arte, Geografía e Historia, 8, pp. 311-354.

Thompson, Edward Palmer (1981), Guerra y decadencia. Gobierno y administración de la España de los Austrias, 1560-1620, Crítica, Barcelona.

Torremocha Silva, Antonio (2006), "Los monfíes de la Alpujarra y la Serranía de Ronda: ¿salteadores de caminos u hombres santos?”, Estudios sobre Patrimonio, Cultura y Ciencias Medievales, 7-8, pp. 277-300.

Urbaneja Ortiz, Catalina (2008), Marbella y su tierra en el tránsito de la época musulmana a la cristiana, Universidad, Málaga.

Vincent, Bernard (1981), "El bandolerismo morisco en Andalucía (siglo XVI)", Awraq, 4, pp. 167-178.

- (1992), "Les morisques grenadins: une frontière intérieure", en Castrum 4. Frontière et peuplement dans le monde méditerranéen au Moyen Âge. Acte du colloque d'Erice, Ecole Française de Rome, Roma, pp. 109-126. 